\title{
DIPUTACION Y GERMANÍA: NUEVA HISTORIA DE UNA APORTACIÓN FINANCIERA ${ }^{1}$
}

\author{
por \\ JOSÉ MARÍA CASTIYLO DEL CARPIO \\ Universidad de Valencia
}

RESUMEN: Es ampliamente conocido desde hace mucho que el reinado de Carlos I se inicio, en el antiguo reino de Valencia, con las "Germantas»; un conflicto social que terminó degenerando en guerra abierta entre los valencianos. En las lineas que siguen a continuación, analizamos los problemas surgidos en la financiación del ejercito formado por el virrey Diego Hurtado de Mendoza desde la optica particular de una de las instituciones que colaboraron en el sostenimiento económico de dicho ejército: la «Diputació del Generals.

Palabras clave. Valencia. Siglo xv. Carlos I. Germanias. Finanzas. Diputaclón.

ABSTRACT: It's widely known, since long time ago, that the reign of Charles I began in the old kingdom of Valencia with the *Germantasn; a social conflict that finished by denerating into a civil war. In the following pages, we try to analyse the problems concemed with the finances of the army organized by the viceroy Diego Hurtado de Mendoza from the perspective of one of the institutions involved in the economic management of this army: the "Diputacio del Generaln.

KEY words: Valence. XVIth century. Charles I. Germanias. Finances. Deputation.

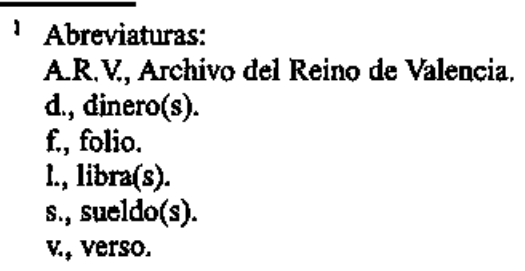

cit., citado(a).

doc., documento/documentación.

ff., folios.

r., recto.

s./núm.., sin número.

Hispania, LVI/2, núm. 193 (1996) 497.515 
No descubriremos nada nuevo, seguramente, si recordamos que dos de los episodios más mitificados de la historia valenciana han sido las Germanías y el progresivo declinar de las instituciones forales valentinas: las primeras, se nos ha dicho, eran el fruto de la conflictiva situación político-social gestada durante el reinado de Fernando el Católico ${ }^{2}$; el segundo, se ha escrito, era el resultado lógico de una discordancia entre la teoría y la práctica del poder cuya manifestación más evidente fue la creciente pérdida de potencial político experimentada por las Cortes, con todo lo que ello comportaba en el diálogo institucional y económico (concesión de servicios) entre el Rey y sus súbditos valencianos ${ }^{3}$.

Nuestra intención, ahora bien, con este trabajo no es reinterpretar la trayectoria politico-institucional valenciana de la época foral; ni reescribir una nueva historia, más o menos integral, de las Germanías que analizara sus diferentes elementos, incluido el conflicto bélico que se desarrolló en 1521 y $1522^{4}$.

No. Nuestro objetivo aquí es mucho más limitado. En efecto, a lo largo de las páginas que siguen a continuación procuraremos exponer una nueva interpretación de un hecho al que autores como Martínez Aloy, García Cárcel o nosotros mismos ya se han referido con anterioridad s: que la Diputación del General valenciana contribuyó a sofocar las Germanías prestando dinero

2 Los mejores estudios publicados hasta la fecha sobre el periodo anterior a las Germanías son: Belenguer Cebrià, Ernesto, València en la crisi del segle XV, Barcelona 1976; Pérez Garcia, Pablo, La comparsa de los malhechores. Un ensayo sobre la criminalidad y la justicia urbana en la Valencia preagermanada (1479-1518), Valencia 1990; PéREz GARCiA, Pablo, El Justicia criminal de Valencia (1479.1707). Una magistratura urbana ante la consolidación del Absolutismo, Valencia 1991, págs. 229-242.

3 Reveladores, en buena medida, sobre este tema son VICENS VIVEs, Jaime, Estructura administrativa estatal en los siglos XVI y XYII: Coyuntura económica y reformismo burgués, Barcelona 1968, págs. 99-141; SALVADOR EsteBan, Emilia, Poder central y poder territorial: Estudis. Revista de Historia Moderna, 12 (1986), págs. 9-28; GL Pujol, Xavier, Notas para el estudio del poder como nueva yaloración de la historia politica: Pedralbes. Revista d'història moderna, 3 (1983); y GonzAlez ANTón, Luis, La Corona de Aragón: régimen poltitico y Cortes. Entre el mito y la revisión historiografica: Anuario de Historia del Derecho Español, LVI (1986), págs. 1017-1042.

4 Sobre las Germanías, aparte de los estudios de R. García Cárcel y E. Duràn que citaremos reiteradamente a lo largo de nuestro trabajo, sigue siendo de consulta inexcusable la obra de VicianA, Martín de, Crónica de la ínclita y coronada ciudad de Valencia, reed. facsímil, 5 vols., Valencia 1972-1980, vol. IV.

5 Martinez Aloy, José, La Diputación de la Generalidad del Reino de Valencia, Valencia 1930, pág. 288; GARCía CARCEL, Ricardo, Las Germanías de Valencia, Barcelona 1975, 1. ed., pág. 177; CASTLL DE CARPIO, José María, La Hacienda foral valenciana a comienzos del siglo XVI. Cortes y Diputación: ForTeA Pérez, José Ignacio, Cremades Gruñan, Carmen María (eds.), Política y Hacienda en el Antiguo Régimen. Actas de la II Reunión Científica de la Asociación Española de Historia Modema, 2 vols., Murcia, 1993, I, págs. 208-209; CAstillo del CaRpio, José Maria, La Diputación de la Generalidad valenciana en un periodo de crisis (1510-1527), Tesis de licenciatura (inédita), Valencia 1993, págs. 133-137 y 152-157.

Hispania, LVI2, núm. 193 (1996) 497-515 
a la Hacienda Real, no obstante las dificultades provocadas en sus finanzas por el desarrollo del conflicto ${ }^{6}$.

\section{INTRODUcción}

Todos los autores que han estudiado este conflicto y sus consecuencias más inmediatas han convenido en señalar, efectivamente, que dentro del prestamismo al que recurrio la Corona para financiar sus operaciones militares deben distinguirse dos facetas; cada una de las cuales se desarrollaría, según parece, en fases cronologicamente diferenciadas: una, privada, que se relaciona con los préstamos concedidos por particulares; y otra, pública, que toma cuerpo con los empréstitos concedidos por instituciones y corporaciones públicas (municipios u organismos diversos dependientes de éstos, gremios, ...) ?

Y es sabido que la Diputación del General se vio involucrada, de una u otra manera, en ambas desde el comienzo mismo de la guerra (junio/julio de 1521). Primero, en la etapa del prestamismo privado, porque el duque de Gandía vendió casi íntegramente sus censales o títulos de la deuda consolidada de nuestra institución en los momentos iniciales de la guerra ${ }^{8}$. Después, en la del prestamismo público, concediendo anticipos a la Hacienda Real a cargo de sus propios fondos. Nosotros, como es fácilmente comprensible, nos centraremos en la segunda; que es la que afectó directamente a sus finanzas.

Bastantes personas se preguntarán, entonces: ¿y por qué volver a escribir sobre un tema del que ya se ha hablado en otros lugares?. A este interrogante podrfamos responder afirmando que nuestro interés se debe a las contradicciones existentes en el seno de la historiografía; pues, cuando se han referido a este tema, los historiadores parecen no haberse puesto de acuerdo: Martinez Aloy, en su clásico sobre la Diputación, habla de 14.700 libras; García Cárcel menciona, en su estudio sobre las Germanías, un préstamo de 12.000

- Sobre este tema, cfr. CASTILlo DEl Cakpio, José Maria, El sistema tributario del Reino de Valencia durante el siglo xvr. Estudis. Revista de Historia Modema, 19 (1993), págs. 121-127; y, del mismo, Una institución valenciana en el umbral de la modernidad: la Diputación del General durante el primer cuarso del siglo XVT. Estudis. Revista de Historia Moderna, 20 (1994), págs. 311-316.

7 Viclana, Martín de, op. cit., IV, págs. 262-263 y 342-345; Garcla CARCEL, Ricardo, Las Germanías de ...., 2. ed., págs. 140-143 y 145-150; DuRÀn, Eulàlia, Les Germanies als Països Catalans, Barcelona 1982, págs. 324-325; PINILlA PÉREZ de Tudela, Regina, Valencia y doña Germana. Castigo de agermanados y problemas religiosos, Valencia 1994, págs. 56-59; PINLLA PéREZ DE TUDELA, Regina, El virreinato conjunto de doña Germana de Foix y don Femando de Aragón, duque de Calabria (1526-1536). Fin de una revuelta y principio de un conflicto, Tesis Doctoral, 2 vols., Valencia 1982, I, pág. 225 .

8 Castillo del. CARPIO, José María, Poder económico y prestigio social. La deuda pública y la Diputación del General a comienzos del siglo Xvr: Pedralbes. Revista d'història modema, 13 (1993), 2 vols., I, pág. 319. Sobre la operación citada en el texto, cfr. también A.R.V., Real Cancillería, Curiae Valentiae, reg. 1408, ff. 3r.-3v. 
ducados, aunque hubiera recogido con anterioridad la cantidad indicada por Martínez Aloy; más recientemente, E. Duràn reducía esa cifra a 2.000 ducados; y, por último, nosotros mismos hemos hablado hace poco tiempo de 14.000 ducados ${ }^{9}$.

Pero, si adujéramos exclusivamente este motivo, estariamos escudándonos, en buena medida, en un planteamiento parcialmente incorrecto; porque esas contradicciones son solo aparentes. Dos observaciones, de carácter eminentemente metodológico, clarificarán bastante las cosas:

- la utilización de dos monedas diferentes (libras y ducados) no debe confundir a nadie; pues el ducado mantuvo durante, al menos, el siglo XVI su cotización en 21 sueldos valencianos ${ }^{10}$. Lo cual equipara nuestros 14.000 ducados a las 14.700 libras de Martínez Aloy ${ }^{11}$.

\section{CUADRO I \\ PRESTAMOS CONCEDIDOS POR IA DIPUTACIÓN A \\ LA HACIENDA REAL (1519.1523), SEGÚN LAS ACTAS QUE SE CONSERVAN :2}

$\begin{array}{ccc}\text { Eecha } & \text { Volor enducados } & \text { Valor en libras } \\ \text { Mayo-1520 } & 2.000 & 2.100 \\ \text { Enero-1522 } & 12.000 & 12.600 \\ \text { Dctubre-1522 } & 2.000 & 2.100\end{array}$

- los errores de lectura e interpretación de algunos autores, como el prof. García Cárcel o E. Duràn, tampoco deben inquietar a quien nos lea; pues son, sin duda, fruto de un trabajo apresurado o superficial: en este sentido, por ejemplo, la cantidad citada por E. Duràn corresponde, en

- Cit. supra, nota 5. Cfr. también: GarCla CArCel, Ricardo, Las Germanías de ...., 2." ed., pág. 146; Ciscar Pallarés, Eugenio, Garcia CARCEL, Ricardo, Moriscos i agemanats, Valencia 1974, pág. 90; y Garcí CÁRCEL, Ricardo, Contes del reinado de Carlos I, Valencia 1972, págs. IX y 11 (a pesar de la flagrante contradicción en la que incurre el autor en esta obra, al indicar en su introducción un dato diferente al establecido en la legislatura de 1528).

10 Cfr. HAMILTON, Earl J., El tesoro americano y la revolución de los precios en España, 1501 . 1650, Barcelona 1983, 2. ed., págs. 123-126.

13 Recuérdese que, como en muchas otras partes de Europa, en Valencia segúa utilizándose durante los siglos xvi y xvir la libra como moneda de cuenta, con sus múltiplos el sueldo y el dinero. La equivalencia entre estas monedas era también la habitual: $1 \mathrm{l}=20 \mathrm{~s}$; $1 \mathrm{~s}$. $=12 \mathrm{~d}$. Todos los cuadros de nuestro artículo expresarán las cantidades en libras (1.), sueldos (s.) y dineros (d.). Vid. Hamilton, Earl J., op. cit., pág. 142. Cfr. Fossier, Robert, La infancia de Europa. Aspectos económicos y sociales, 2 vols., Barcelona 1984, II, págs. 880-898; PouNDS, N. J. G., Historia económica de la Europa medieval, Barcelona 1987, 3. ed., págs. 95-96 y 140; Cipolla, C. M., El gobierno de la moneda. Ensayos de historia monetaria, Barcelona 1994, págs. 37-43. La mejor síntesis sobre esta materia que conocemos es Spurforo, Peter, Dinero y moneda en la Europa medieval, Barcelona 1991.

12 FUEnTE: A.R.V., Generalidad, Provisions, reg. 2972, ff. 167r-169v., 322r.-325v., 332r., 348v.350r. y $475 \mathrm{v}-477 \mathrm{r}$.

Hispania, LVV/2, mín. 193 (1996) 497-515 
realidad, a un préstamo (el primero de 2.000 ducados) no desembolsado cuya destinataria deberia haber sido la Real Audiencia ${ }^{13}$.

Así pues, nuestro interés al abordar una vez más este asunto es acometer, en la medida de lo posible, una serie de interrogantes que esperan todavía ser respondidos: ¿cuándo hizo efectivo la Diputación el dinero prestado a la Corona?, ¿a quién se entreg6? ¿cómo es posible que la Diputación concediera esos préstamos cuando el cronista Viciana nos dice que los agermanados controlaban, por estas fechas, la actividad de dicha institucion; impidiendo la ejecución de bastantes compromisos económicos? $14 ; \ldots$; y, por paradójico que pueda parecer, $i$ a cuánto ascendió el dinero desembolsado en la práctica por la Diputación?.

\section{EL INICIO DE LOS CONTACTOS VIRREYIDIPUTACIÓN}

Determinar cuánto dinero se gastó, realmente, la Diputación en la financiación de los a... salaria hominum peditum et equitum ac alias expensas exercitus regalis comoratis (...) contra perfidos agermanatos ...) ${ }^{15}$ o el momento desde el cual sus finanzas se vieron inmersas en ella no es, sin embargo, una tarea grata y sencilla. Ciertas cuestiones elementales, que la documentación deja en la penumbra, cuando no en la oscuridad, se encargarán de entorpecer nuestra labor.

Uno de los aspectos que, seguramente, nunca lleguemos a conocer con exactitud es el que se refiere al inicio de los contactos para mezclar a la Diputación en ese prestamismo público al que nos referíamos con anterioridad. En efecto, coincidiendo en el tiempo con el abandono de Valencia-ciudad por las principales autoridades y el desarrollo de las primeras actuaciones bélicas (mayo/junio de 1521), los libros de actas y escrituras de nuestra institución inician un silencio que abarca buena parte del verano de ese año; es decir, cuando el furor agermanado alcanzaba su auge en la capital del Reino ${ }^{16}$.

13 Duràn, Eulàlia, op. cit., pág. 179. Cfr., sin embargo, Castillo del Carpio, José María, la Hacienda foral ...., pág. 209 y, más detalladamente, La Diputación de ...., págs. 153-154. La prof. Duràn, además, comete el error de confundir a los contadores (oficiales de la Diputación) con ucompradors de drets» (arrendatarios de impuestos).

14 ViCLANA, Martín de, op. cit., IV, pág. 223.

15 Texto extractado de: A.R.V., Generalidad, Protocolos, reg. 2750, ápoca de 9-sept.-1521. Sobre el contenido y naturaleza de las ápocas, cfr. CASTILLO DEL. CARPIO, José María, Fuentes para el estudio de la Diputación foral valenciana (Siglos XV1-XVI): Saitabi. Revista de la Facultat de Geografia i Història (Universitat de València), 44 (1994), pág. 49

16 La exposición más detallada sobre los acontecimientos a los que nos referimos sigue siendo la de Viciana, Martín de, op. cit., Iv, págs. 98-108 y 379-381. Cfr. A.R. V., Generalidad, Protocolos, reg. 2750 (año 1521), con una interrupción que se alarga del 29 de mayo al 9 de septiembre; e IDEM, Generalidad, Provisions, reg. 2972 (años 1521 a 1523), cuyo periodo de carencia cronológica abarca del 29 de mayo al 1 de noviembre de 1521. Sobre la naturaleza de nuestras fuentes de información al respecto, vid. Castillo del Carpio, José Maria, Fuentes para el ...., págs. 46 y ss. 
Ahora bien, a pesar de eso diversas referencias nos han permitido situar el inicio de las conversaciones entre los oficiales de la Diputación y los máximos dirigentes del bando antiagermanado en algún momento del periodo comprendido entre el 29 de mayo y el 29 de julio del año 1521. En efecto, cuando empieza ese mutismo documental ahora citado -el 29 de mayo de 1521-, ninguna entrevista sobre este tema parecía haber sido concertada; cuando finaliza, sin embargo, Bernat Despuig, Maestre de la Orden de Montesa y diputado por aquel entonces, reconocía - a través de diferentes recibos o ápocas- haber estado entregando algunas cantidades a miembros del ejército y administración reales

«... habens comissionem aliorum condeputatorum dicti generalis (...) cum provissione sive ordinacione manibus nostris et aliorum dictorum nostrorum condeputatorum firmata in campo regali villae de Nulles [diae] vicesimo nono mensis julii proxime preteriti ...» 17 .

Es decir, que el 29 de julio de 1521 los oficiales de la Diputación habían adoptado ya en firme una decisión sobre el asunto que aquí nos ocupa. Por eso, más adelante, en enero de 1522 y febrero del año 1549, algunos oficiales de la Diputación recordaban que, estando ellos y el escribano de la institución en el campamento real instalado en Nules, habian recibido del virrey una petición de ayuda económica ante la cual $\alpha . .$. feren electíó de persones que anassen per lo Regne a exhigir e cobrar les pecunies degudes al General (...) per a poder subvenir promptament a la (...) regia cort .... ${ }^{18}$.

Unas manifestaciones, apoyadas en abril de 1522 por la Cancillería virreinal ${ }^{19}$, a tenor de las cuales podemos afirmar que las finanzas de nuestra institución fueron involucradas en el prestamismo público desde el comienzo mismo de la contienda; corrigiendo, en buena medida, lo que inturamos hasta la fecha. Pero no se trata sólo de eso; ya que facilitan también una información de suma importancia para comprender, en su justa medida, el silencio documental al que nos referíamos líneas más arriba: que muchas de las decisiones adoptadas por los diputados durante el verano de 1521 lo habian sido de palabra, sin mediar acto documental alguno ${ }^{20}$. Dicho de otra forma: que esa laguna documental muy posiblemente no se debiera s6lo a una desorganización burocrática, relacionada con alguna dejación - forzada o no- de

\footnotetext{
17 A.R.V., Generalidad, Protocolos, reg. 2750, ápoca de 9-sept.-1521 firmada por el citado Bernat Despuig.

18 A.R.V., Generalidad, Procesos y papeles varios, reg. 2520, ff. s./núm.; IDEM, Generalidad, Provisions, reg. 2972, ff. 90r.-90v., 91v.-92r. y 167r.-169v.; IDEM, Generalidad, Protocolos, reg. 2750, ápocas de 9-sept., 15-sept., 19-sept. y 22-sept.-1521; 1 bidem, reg. 2775, acta de 19-febrero1549. Cff. ViclanA, Martín de, op. cit, IV, págs. 343-346 y 367; y DuRAN, Eulàlia, op. cit., pág. 193.

19 A.R.V., Generalidad, Procesos y papeles varios, reg. 2520 , ff. s./núm.. Sobre la Cancillería valenciana, cfr. CANET APARISI, Teresa, La Magistratura valenciana (siglos XVI-XVI), Valencia 1990, págs. 21 y ss.

20 Doc. cit. supra, nota 17 y 18.
}

Hispania, LVI2, nưm 193 (1996) 497.515 
funciones por parte de los diputados, sino también a una táctica para burlar el pretendido control de Ios agermanados valentinos sobre el aparato burocrático de la Diputación que hubiera podido permanecer organizado en la ciudad de Valencia ${ }^{21}$.

Quizás, por todo ello, en enero de 1522 los oficiales de la Diputación, reunidos para «legalizar" los pagos posteriores a la petición virreinal y autorizar el abono de la cantidad que restara hasta 12.000 ducados, afirmaran no tener un conocimiento muy exacto del dinero entregado hasta ese momento a la Hacienda Real: 9.000 libras, confesaban; o cerca de ellas ${ }^{22}$. Quizás, también, por todo ello, la propia contabilidad de la Diputación parezca contagiarse de ese mutismo que comentábamos antes. Los pagos especificados en ella por anticipos concedidos a la Corona durante las Germanias, en efecto, ascienden "sólo» a 5.801 libras-19 sueldos: 8.898 libras-1 sueldo menos de las 14.700 a las que nos referfamos anteriormente ${ }^{23}$. Mientras que, a la vez, los balances contables de estos años, efectuados cuando casi Carlos I conclúa su reinado, sólo nos brindan una visión descriptiva y genérica de todo el proceso aquí estudiado ${ }^{24}$.

\section{CUADRO II \\ PAgOS EFECTUADOS POR LA DIPUTACIÓN EN CUMPLMMENTO DE SUS ACUERDOS CON LA IACIENDA REAL; SEGÚN SU PROPA CONTABMIDAD*}

\begin{tabular}{|c|c|c|c|c|c|}
\hline \multicolumn{3}{|c|}{1522} & \multicolumn{3}{|c|}{1523} \\
\hline Fecha albarón & Destinatario & Cantidad & Fecha albarón & Destinatario & Contided \\
\hline 7 -oct.-1522 & Varios (a) & $1.653 \mathrm{l} .19 \mathrm{~s} .1 \mathrm{~d}$. & $19-$ sept. -1523 & G. F. Cruylles & $1.575 \mathrm{l}$. \\
\hline 7 -oct.-1522 & J. Beneyto & $551 \mathrm{l} .4 \mathrm{~s} .11 \mathrm{~d}$. & 21-oct.-1523 & G.F. Cruylles & $150]$. \\
\hline 15-oct. 1522 & M. de la Torte & 5251. & 28-nov.-1523 & F. Artés (b) & 3751. \\
\hline 25 -oct. 1522 & P. de P. Andreu & $5511.15 \mathrm{~s}$ & & & \\
\hline 30 -oct.-1522 & C. de la Torre & 4201. & & & \\
\hline Total & & $3.701 \mathrm{l} .19 \mathrm{~s}$. & & & 2.1001. \\
\hline
\end{tabular}

Fuentes: A.R.V., Generalidad, Claverfa, reg. 787, ff. 290r., 292v y 294r.; Ibidem, reg. 786, ff. 282v. y 287r.-288r.; IDEM, Generalidad, Albaranes, reg. 90, ff. 31r.-34v,; Ibidem, reg. 91, ff. 32v.-33v,, 35v. 36 r. y $37 \mathrm{r} .-37 \mathrm{v}$

(a) G. F. Cruylles (doncel), F. de Artés (dor. en ambos dos) y A. Usodemar (mercader genovés).

(b) G. F. Cruylles y F. de Artés.

\section{LA APORTACIÓN TOMA CUERPO: ALGUNAS CONSIDERACIONES SOBRE SU CUANTÍA}

En todo caso, otros testimonios vienen a ratificar que la Diputación del General entregó a la Hacienda Real desde el verano mismo de 1521 más de

21 Cit. supra, nota 14.

22 A.R.V., Generalidad, Provisions, reg. 2972, ff. 167r.-169v. (acta de 19-enero-1522).

23 Cfr. supra, notas 9 a 12; CuADRo 1; e infra, CuADro II.

24 A.R.V., Generalidad, Protocolos, reg. 2775, actas de 19-feb. y 16-marzo-1549; Ibidem, reg. 2779, acta de 22-dic.-1553. 
5.801 libras-19 sueldos; y lo hacen aportando cifras concretas: las presentadas en los CuADros III y IV 25 .

Según podría desprenderse de las cantidades que hemos alegado hasta ahora ${ }^{26}$, el mayor esfuerzo económico de la Diputación debió producirse durante los meses iniciales de la contienda: en efecto, aceptando - no sin ciertos temores - lo que nos dice una contabilidad - como es la de nuestra institución-incompleta en lo relativo al ejercicio económico del año 1521 y corrigiéndolo, podríamos afirmar que la Diputación gastó entre julio y diciembre de 15218.898 libras-1 sueldo; 3.701 libras-19 sueldos en 1522; y 2.100 libras durante 1523. Pero una serie de matices y correcciones, sin modificar en lo esencial esta periodización cambiarán la imagen que acabamos de describir; la imagen, sobre todo, que nos ofrecen esos testimonios en los que nos hemos basado para construir los CuADRos III y rv.

Todo parece indicar, en primer lugar, que los desembolsos de la Diputación durante el segundo semestre de 1521 fueron ligeramente inferiores a lo que nos dan a entender sus propios libros de contabilidad. De acuerdo con los testimonios que nos han dejado Alfonso Sanchis Dalmau y Diego Hurtado de Mendoza, dichos desembolsos ascendieron a 7.546 libras-19 sueldos-3 dineros; que se incrementan hasta 8.670 libras-8 sueldos-11 dineros según incluyamos o no en este total las 1.123 libras-9 sueldos-8 dineros percibidas - según parece- por Tomás Guerau y Ausias Martí: lo dicho por uno u otro varía porque el único elemento del que disponemos para datar esta partida es la afirmación del virrey en la cual se reconoce haber recibido dicha cantidad con anterioridad al 19 de enero de 1522, sin especificar, por desgracia, su fecha exacta ${ }^{27}$. Si bien, de forma similar a lo que nos ocurría anteriormente con la fecha en la cual se iniciaron los contactos entre la Diputación y los oficiales reales, éste es un punto cuya resolución precisa nunca sea, quizás, posible con las pruebas que actualmente obran en nuestro poder.

25 En el CuAdro Iv, el total asciende a 14.699 libras-19 sueldos por un error cometido en el documento que le sirve de base: en el asiento cuyos titulares son Gaspar Felipe Cruylles y otros, se escribieron 18 sueldos en lugar de 19 (A.R.V., Maestre Racional, Tesorería General, leg. 8848, ff. 75r.-76v;; IDEM, Generalidad, Procesos y papeles varios, reg. 2520, ff. s./núm..; IDEM, Generalidad, Quem de deutes del General (1508-1526), reg. 4977, ff. 34v.-38r. Sobre la errata comentada en esta nota, cfr. supra e infra, CuADRos II y Iv).

26 Los que nos ofrece la contabilidad de la Diputación (Cuadro in), se entiende.

27 En este sentido, debemos señalar --como ha quedado de manifiesto en el CUADRO IV- que Sanchis Dalmau tampoco data esta partida. Además, hemos matizado "según parece» porque las fuentes no dejan muy claro quién recibió en la realidad dicha partida (A.R.V., Generalidad, Procesos $y$ papeles varios, reg. 2520 , ff. s./núm.. (reconocimiento de deuda expedido por orden de Hurtado de Mendoza); y A.R.V., Generalidad, Protocolos, reg. 2754, ápoca de 18-nov.-1523 (firmada por Sanchis Dalmau a los diputados). De esta ápoca, sólo hemos podido consultar un extracto; que es el documento citado en el mencionado CUADRo Iv).

Hispania, LVI/2, núrm. 193 (1996) 497-515 


\section{CUADRO III}

\section{PERSONAS QUe Cobraron Ei. PREstamo de 12.000 ducados;} SEGÚN LOS DOCUMENTOS INDICADOS AL PIE

Destinotario
B. Ciurana
M. Junyent
B. de Cardona
R. R. de Corella
Micer Soriano
[?] Tristany
J. Ram Scrivà
P. Gomis
M. P. de Almaçan
A. Martír. Guerau
F. Artés y otros
G. F. Cruylles
S. Centelles
M. Corts
Varios

Brof/cond. social
Batle de Morella
Capitán de infantería
Capitán de infanterfa
Conde de Cocentaina
Capitán de infanterfa
Mestre Racional
Notario
Mercader
Mercader
Doncel
C. de Oliva
Procó. de A. Sarchis
Correos y otros gastos

\begin{tabular}{|c|c|}
\hline \multicolumn{2}{|c|}{ Cantidades } \\
\hline Sequin el doc. (A) & Sepúneldoc, $(B)$ \\
\hline $2.1301 .14 \mathrm{~s} .1 \mathrm{~d}$ & $2.1301 .14 \mathrm{~s} .1 \mathrm{~d}$ \\
\hline $531,11 \mathrm{~s}$. & $53 \mathrm{l}, 11 \mathrm{~s}$. \\
\hline $32 \mathrm{l} .11 \mathrm{~s}$ & 32l. $11 \mathrm{~s}$. \\
\hline $2.8691 .3 \mathrm{~s}$. & $2.8691 .3 \mathrm{~s}$. \\
\hline $\begin{array}{l}11 \mathrm{l} .11 \mathrm{~s} . \\
211 .\end{array}$ & $\begin{array}{l}11 \mathrm{~L} 11 \mathrm{~s} \\
21 \mathrm{~L}\end{array}$ \\
\hline 203 I. $13 \mathrm{s.} 4 \mathrm{~d}$. & $203 \mathrm{l}, 13 \mathrm{~s} .4 \mathrm{~d}$. \\
\hline $1.100 \mathrm{I}$ & $1.100 \mathrm{~L}$ \\
\hline 5251. & 5251. \\
\hline $1.123 \mathrm{l} 9 \mathrm{s.} 8 \mathrm{~d}$. & $1.123 \mathrm{l} .9 \mathrm{~s} .8 \mathrm{~d}$. \\
\hline 3.1501. & \\
\hline $126 \mathrm{l} .19 \mathrm{s.} 6 \mathrm{~d}$. & \\
\hline 3001. & 3001. \\
\hline $\begin{array}{c}855 \mathrm{l} .6 \mathrm{~s} .3 \mathrm{~d} . \\
97 \mathrm{l} .1 \mathrm{~s} .2 \mathrm{~d} .\end{array}$ & $\begin{array}{r}202 \mathrm{l} .14 \mathrm{~s} .8 \mathrm{~d} . \\
97 \mathrm{l} .1 \mathrm{~s} .2 \mathrm{~d} .\end{array}$ \\
\hline
\end{tabular}

(A) A.R.V., Maestre Racional, Tesoreria General, leg. 8848, ff. 75r.-76v.

(B) A.R.V., Generalidad, Procesos y papeles varios, reg. 2520, ff, s. $\mathrm{n}^{\circ}$.

CUADRO IV

APORTACIÓN DE LA DIPUTACIÓN AL SOSTENIMIENTO DEL EJÉRCTTO ANTIAGERMANADO SEgÚN EL APOCA FIRMADA POR EL TESORERO REAL*

\begin{tabular}{|c|c|c|c|}
\hline Fecha & Bapado nor & d & Cantided \\
\hline 28-jul_/oct-1521 & Bernat Despuig & B. Ciurana & $2.969 \mathrm{l} .2 \mathrm{~s} .11 \mathrm{~d}$ \\
\hline 13-nov.-1521 & Fo. Darto & Conde de Cocentaina & $2.074 \mathrm{~L} 3 \mathrm{~s}$ \\
\hline 17-nov-1521 & $\mathrm{F}^{\mathrm{co}}$. Darto & Conde de Cocentaina & $375 \mathrm{l}$. \\
\hline 22-nov-1521 & Hieronym Bayona & Mestre Racional & $203 \mathrm{l} .13 \mathrm{s.} 4 \mathrm{~d}$ \\
\hline 9-dic.-1521 & Hieronym Cervera & Conde de Oliva & $300 \mathrm{~L}$ \\
\hline 20-dic.-1521 & Bernat Despuig & Pere Gomis, notario & $1.100 \mathrm{l}$ \\
\hline \multirow[t]{2}{*}{ 23-dic.-1521 } & $F^{\infty}$. Darto & M. Pérez de Almazán & $525 \mathrm{l}$. \\
\hline & T. Guerau/A. Martí & & $1.123 \mathrm{l} .9 \mathrm{s.} 8 \mathrm{~d}$ \\
\hline 7-oct-1522 & & G. F. Cruylles y otros & $1.6531218 \mathrm{~s} .1 \mathrm{~d}$ \\
\hline 7-oct.-1522 & & Joan Beneyto, mercader & $551 \mathrm{l} .4 \mathrm{~s} .11 \mathrm{~d}$ \\
\hline 15-act.-1522 & & Miquel de la Torre & $525 \mathrm{~L}$ \\
\hline 25-oct.-1522 & & Pere de Pere Andreu & $551 \mathrm{l}, 15 \mathrm{~s}$. \\
\hline \multirow[t]{3}{*}{ 30-oct. 1522} & & Cristóbal de la Torre & 4201. \\
\hline & $F^{\infty}$. Darto & Miquel Cartés & $25 \mathrm{l} .5 \mathrm{s.} 8 \mathrm{~d}$. \\
\hline & Bernat Joan Roig & Alfonso Sanchis & $202 \mathrm{l} .6 \mathrm{~s} .5 \mathrm{~d}$. \\
\hline 19-sept-1523 & & G. F. Cruylles & $1.575 \mathrm{~L}$ \\
\hline 21-oct.-1523 & & G. F. Cruylles & $150 \mathrm{~L}$ \\
\hline 28-now-1523 & & F. ArtésiG. F. Cruylles & $375 \mathrm{~L}$ \\
\hline Total & & & $14.699 \mathrm{l} .19 \mathrm{~s}$. \\
\hline
\end{tabular}

Hispania, LV1/2, núm. 193 (1996) 497.515 
En efecto, Berenguer Ciurana - batle de Morella- recibio durante los seis últimos meses del año 1521 de Bernat Despuig más dinero del que Sanchis Dalmau o Hurtado de Mendoza declararon conocer: ignorando un sutil error de suma ${ }^{28}$, ambos oficiales reales indican que Ciurana había cobrado, desde el 9 de septiembre de 1521, 1.811 libras-14 sueldos-1 dinero en ocho partidas 29. Lo cual no es totalmente correcto, porque no recogen otros dos pagos cuyas ápocas hemos podido consultar: uno de 69 libras- 5 sueldos-4 dineros y otro de 35 libras- 3 sueldos- 5 dineros ${ }^{30}$, que Berenguer Ciurana recibio en su condición de "procuratori magnifici Alfonsi Sanchis (...) et habenti officium solvendi salaria hominum peditum et equitum ac alias expensas exercitus regalis quem tenet in villa de Nulles Illis (...) vice rex et capitaneus generali prefate $\mathrm{C}^{\mathrm{e}}$ $\mathbf{R}^{\mathrm{e}} \mathbf{M}^{\text {atis }}\left(\right.$...) contra perfidos agermanatos" ${ }^{3 t}$.

Durante el segundo semestre de 1521, así pues, y contando con que hayan llegado hasta nosotros los justificantes de todas las cantidades entregadas a la Hacienda Real, la Diputación habría desembolsado 8.774 libras-17 sueldos-8 dineros: las 8.670 libras-8 sueldos-11 dineros señaladas por los oficiales reales más las 104 libras-8 sueldos-9 dineros de los dos pagos indicados en el párrafo anterior. $¿$ Fue éste el total realmente abonado por la Diputación a lo largo de la segunda mitad de 1521?. Siempre nos quedará la duda, porque es todavía ligeramente menor a lo que dan a entender los libros de contabilidad de la propia Diputación ${ }^{32}$; pero, sobre todo, porque algunos pagos de los que conocemos fueron ejecutados constando nada más que la pertinente orden verbal ${ }^{33}$. Es decir, que, al hablar de este periodo, nunca podremos saber si el

28 La cuantía de las ocho partidas comentadas a continuación asciende a 1.811 libras-13 sueldos-2 dineros, si sumamos los importes de todas ellas especificados en el documento $B$ del CuADro III; ó 1.811 libras-14 sueldos-2 dineros, si utilizamos las ápocas de esos ocho pagos (Vid. supra, CuADRO III -doc. ( $B$-_; y A.R.V., Generalidad, Protocolos, reg. 2750, ápocas de fechas 9-sept., 15sept., 19-sept., 22-sept., 27-sept. y 28 sept.-1521).

29 Que se incrementan hasta 2.130 libras-14 sueldos-1 dinero si les añadimos 319 libras que el ya citado Maestre de Montesa aportó a las arcas reales de su propio bolsillo. La inclusión de esta cantidad en las partidas recibidas por B. Ciurana a cargo de los préstamos concedidos por la Diputación, puede ser interpretada como una devolución de las 319 libras al Maestre (Vid. supra, CuADRO II; A.R.V., Generalidad, Procesos y papeles varios, reg. 2520, ff. s./núm.; ibidem, reg. 2527, ff. s./núm.; e IDEM, Generalidad, Quem de deutes del General (1508-1526), reg. 4977, ff. 31v.-33v.).

30 A.R. V, Generalidad, Protocolos, reg. 2750, ápocas de 10-oct. y 14-oct-1521. Cfr. A.R.V., Generalidad, Procesos y papeles varios, reg. 2527, ff. s./núm..; e IDEM, Generalidad, Quern de deutes del General (1508-1526), reg. 4977, ff. 31v.-33v.

31 Cita extraída de A.R.V., Generalidad, Protocolos, reg. 2750, ápoca de 15-sept.-1521. Sobre el nombramiento de Ciurana, cfr. Viclana, Martín de, op. cit., IV, pág. 345; y Garcla CÁrCel, Ricardo, Las Germanías de ...., 2." ed,, pág. 141

32 Doc. Cit. supra, CuADRo II.

33 Así lo indicaba el virrey Hurtado de Mendoza, en el documento con el cual aceptaba las condiciones impuestas por los of iciales de la Diputación para hacer efectivos en su integridad los 12.000 concedidos el 19 de enero de 1522, cuando reconocía el dinero recibido con anterioridad a esa fecha (A.R.V., Generalidad, Procesos y papeles varios, reg. 2520, ff. s./núm..; IDEM, Real Cancillería, Itinerum lugartenencia Mendoza y Cavanilles, reg. 414, ff. 3r.-4r. Cit. supra, nota 19).

Hispania, LVI/2, núm. 193 (1996) 497-515 
virrey o el loctinent de general tresorer "olvidaron» contabilizar alguna partida o no; al menos, con nuestros actuales conocimientos sobre la materia.

Es posible, en segundo lugar, que la actuación de Ciurana como intendente real en las comarcas norteñas del reino valenciano, que le permitio administrar importantes sumas de dinero ${ }^{34}$, diera lugar a algún tipo de equívoco al dificultar la distinción entre el dinero recibido por él con cargo a las arcas de nuestra institucion y las cantidades entregadas por otras corporaciones o por particulares. No debemos olvidar - al hablar de este asunto- que el nombramiento de un elevado número de receptores provoc6, como mínimo, un considerable caos en las finanzas del ejército antiagermanado ${ }^{35}$.

\title{
CUADRO $\mathbf{v}$
}

DISTRUBUCIÓN REAL DE LAS CANTIDADES QUE $B$.

\section{CIURANa COBRó, SEgt́n EL documento CITAdo EN EL CUADRo IV ${ }^{36}$}

$\quad$ Titular
Berenguer Ciurana
Miquel Junyent
Baltasar Cardona
micer Soriano
[?] Tristany
Varios
Miquel Corts
R. Rois de Corella
Total

\author{
Cantidad \\ 2.130 I. 14 s. $1 \mathrm{~d}$. \\ $531.11 \mathrm{~s}$. \\ 321. $11 \mathrm{~s}$. \\ 111. $11 \mathrm{~s}$. \\ 211. \\ 971.1 s. 2 d. \\ 2021. 14 s. 8 d. \\ 4201. \\ 2.9691. 2 s. 11 d.
}

Diferentes extractos contables, que enumeran correlativamente sumas entregadas a Ciurana por ministros de la Diputacion o por responsables de algunos municipios del Maestrazgo valenciano, asi parecen confirmarlo, ofreciendo una sensación de anarquía ${ }^{37}$. No discutiremos, por eso, que la falta de experiencia en el uso y elaboración de registros contables fuera el motivo principal por el cual Alfonso Sanchis atribuyó, en noviembre de 1523, a Berenguer Ciurana algunas cantidades cuyos destinatarios habian sido otras personas; $o$, al menos, no lo haremos mientras no se conozca el veredicto de

${ }^{34}$ Fue él, por ejemplo, quien recibió del «... Senyor Mestre de Montesa y de sos vasalls ...» los desembolsos realizados por algunas poblaciones del Maestrazgo; que, para ayudar a financiar al ejército real, pagaron directamente el salario de cierto número de soldados (A.R.V., Generalidad, Procesos y papeles varios, reg. 2527, ff. s./ním.. Algunas de las cantidades indicadas en este documento corresponden con las citadas en VICIANA, Martín de, op. cit., pág. 345; y DURAN, Eulàlia, op. cit., págs. 324-325).

35 Cfr. Garcla CARCel, Ricardo, Las Germanias de ..., 2." ed., págs. 140-141.

36 Fuente: Elaboración propia a partir de los datos consignados en los CuADros ti y rv.

37 Doc. cit. supra, notas 29 y 34. 
los dos visitadores enviados por el rey en 1567 para revisar la gestión de los diversos receptores que habían gestionado las finanzas del ejército real durante el conflicto. Es decir, que no emitiremos un juicio mientras no conozcamos porqué las 420 libras cuyo titular era $\mathrm{R}$. Rois de Corella, conde de Cocentaina, no fueron contabilizadas en el correspondiente libro de la tesorería real hasta el año $1567^{38}$.

$$
* * *
$$

Pero si el caos, cuanto menos, parece envolver la gestión de Ciurana, también los demás oficiales reales que cobraron dinero de la Diputación se ven afectados por esa pretendida descoordinación contable.

Cierto es, efectivamente, que la unanimidad es la nota en la documentación cuando se habla sobre el dinero percibido por Joan Ram Scrivà ${ }^{39}$; lo cual nos dispensará de prestarle atención. Ahora bien, ¿cómo debemos interpretar las importantes discrepancias que existen entre unos documentos y otros al citar las sumas recibidas por Miquel Corts ${ }^{40}$ ?; ¿por qué el loctinent de general tresorer, Alfonso Sanchis, es mencionado en el documento que nos ha servido para construir el CuADRo $\mathrm{N}$ y, sin embargo, no lo es en los utilizados en la elaboración del CUADRO III? ${ }^{41}$.

Realmente, la impresión que uno saca al estudiar este asunto es que los diferentes balances de la tesorería general en los que se cuantificaba el apoyo financiero de la Diputación ${ }^{42}$ al ejército antiagermanado fueron cuadrados artificialmente para hacerlos coincidir con el límite de gasto - 14.700 librasestablecido al conceder empréstitos a la Hacienda Real 43; no consiguiéndolo,

3B En ese libro se recogen las cuentas de lo recibido por el conde de Cocentaina; al margen de lo que dice el balance de la tesorería real citado en el CuAdro in (A.R.V., Maestre Racional, Cuentas de las Germanías (1567), reg. 9880, asiento de 7-abril-1567; cfr. A.R.V-, Generalidad, Quern de deutes del General (1508-1526), reg. 4977, f. 34v.; e IDEM, Maestre Racional, Tesorería General, reg. 8848 , f. 75 r. Sobre este asunto, lo único que sabemos es lo poco que dice GarCia CARCEL, Ricardo, Las Germanías de ...., 2." ed., págs. 140-141).

39 Doc. cit. supra, CuAdros II y iv; cfr. A.R.V., Maestre Racional, Tesorería General, reg. 10161, f. 14v. (asiento de fecha 23-nov-1521).

40 Procurador de Alfonso Sanchis, es denominado «Regent lo offici de thesorer general de Valencian por el virrey en septiembre de 1522 (La cita que encabeza esta nota está sacada de A.R. V., Real Cancillería, Itinenum lugartenencia Mendoza y Cavanilles, reg. 414 , f. $3 r$.).

41 En este sentido, antes de continuar debemos aclarar que ignoramos a cuál de los dos personajes que ejercieron como tesoreros reales en el reino valentino durante las Germanías se refiere el documento citado en el CUADRO IV; ya que éste no permite identificarlo: Alfonso Sanchis, fallecido a mediados de 1522; o su hijo, Alfonso Sanchis Dalmau. Aunque otras fuentes utilicen, normalmente, los dos apellidos del segundo para identificar al uno del otro (Cit. en Garcta CARCEL, Ricardo, Las Germanías de ...., $2^{\mathbf{2}}$ ed., págs. 141-142; cfr. Castlllo del CARP1o, José María, Poder económico y...., pág. 321 nota 20).

42 Vid. supra, CUADRO III -documento ( $A$ )-; y doc. cit. en el CUADro Iv. Cfr. supra, notas 27 y 33 .

$$
43 \text { Vid. supra, CuADRO } 1 .
$$

Hispania, LV12, núm. 193 (1996) 497-515 
encima, plenamente: la copia del ápoca firmada por Alfonso Sanchis Dalmau a los diputados en noviembre de 1523 que hemos podido consultar, al menos, comete un pequefo error al atribuir a Gaspar Felipe Cruylles, Francesc de Artés y Antoni Usodemar el cobro de 1.653 libras-18 sueldos-1 dinero ${ }^{44}$.

Y se alcanza esta conclusión, básicamente, por dos motivos: primero, porque la única partida directamente abonada a Sanchis y Corts de cuya existencia quedó reflejo documental en los libros de cuentas de la tesorería general y en los balances que mencionábamos líneas atrás son las 214 libras14 sueldos-8 dineros atribuidas a Miquel Corts por el virrey ${ }^{45}$; mientras que, por el contrario, otras cantidades consignadas en esa contabilidad no fueron recogidas luego en los precitados balances ${ }^{46}$. Y segundo, por la coincidencia existente entre los ingresos de Alfonso Sanchis y su procurador Corts que se recogen en el CuADro rv (227 libras-12 sueldos-1 dinero) con el resultado de la siguiente operación ${ }^{47}$ : Gastos relativos al año 1521,
que cita el virrey

Gastos de 1522 y 1523 , que recoge la contabilidad de la Diputación

TOTAL

DIFERENCIA con las 14.700 libras 8.670l. 8 s. $11 \mathrm{~d}$.

$5.8011 .19 \mathrm{~s}$.

14.4721. 7 s. $11 \mathrm{~d}$.

- 227 l. 12 s. $1 \mathrm{~d}$.

Esta coincidencia, es cierto, puede inducirnos a pensar que el ápoca a partir de la cual hemos confeccionado el CuADro iv se elaboró tomando como base los datos indicados por el virrey y por los libros de claveria de la Diputación. Pero no por eso deja de transmitirnos la falta de profesionalidad de la tesorería real; la anarquía, en última instancia, reinante en la organización que gestionó las finanzas del ejército formado para derrotar a los agermanados: ante una constatación como la que acabamos de presentar, ¿quién podría resistirse a la imagen de un tesorero real que no sabe cuánto dinero debe exactamente a la Diputacion y decide ofrecer un balance ficticio?. Nosotros, desde luego, no; aunque, con esta postura, tampoco queramos ocultar que la Dipu-

44 Cuando deberian haber sido 1.653 libras- 19 sueldos-1 dinero - la suma especificada en los libros de cuentas de la propia Diputación - para establecer el total en la 14.700 libras citadas. Sin duda, nos encontramos - en este caso- ante un simple error de transcripción (Vid supra, CuARos II y IV; cit. supra, nota 25 ).

45 Vid. supra, CUADRO ill - documento (B)-; cfr. A.R.V., Maestre Racional, Tesorería General, reg. 10161, f. 14v. (asiento de 9-oct.-1521; abonado por el Maestre de Montesa).

46 Es el caso de un abono de 25 libras-9 sueldos, datado el 25 de enero de 1523 , mencionado en cierto libro (ya citado) de la tesoreria general (A.R.V., Maestre Racional, Tesorería General, reg. 10161, f. 14v., asiento de 25-enero-1523; CUADRo III, -documento ( $A$ - - y CUADro IV).

${ }^{47}$ Las FUENTES utilizadas para la elaboración del siguiente estaditlo han sido: doc. cit, supra, CUADRo II; y CUADRo III, doc. $(B)$. 
tación pudo tener buena parte de "culpabilidad en todo ese desorden al desconocer -oficialmente, al menos- el importe del dinero prestado a la Hacienda Real durante el segundo semestre del año 1521.

En este sentido, desde luego, es posible que influyera también poderosamente otro aspecto: que la Diputación no entregó directamente a los administradores de las finanzas regias muchas de las cantidades desembolsadas para socorrer a la Hacienda Real.

En efecto, bastantes de esas sumas fueron empleadas para abonar directamente gastos diversos. Es el caso, por ejemplo, de las cobradas por los diferentes capitanes de infantería que figuran en nuestros cuadros - cuyos sueldos y los de aquellos soldados que se encontraban a su órdenes sufragaron, parcialmente al menos, los diputados por mandato del virrey- ${ }^{48} \mathrm{o}$ las satisfechas -también, tras el oportuno "encargo" virreinal- a diversos correos y "trompetas» en retribución de sus servicios. Unos gastos que, efectuados todos ellos durante la segunda mitad de 1521, deben ser los que atribuye Viciana al «reyno de Valencia cuando comenta las ordenes cursadas por Diego Hurtado de Mendoza tras su desembarco en Peñíscola (julio de 1521) ${ }^{49}$.

Como también lo es de aquellas otras partidas que ja Diputación destinó para hacer frente a sumas que ya había recibido previamente el erario regio. Unas son las 3.701 libras-19 sueldos que el oficial encargado de gestionar los cobros y pagos de la Diputación -el clavari rebedor-abonó durante 1522 para liquidar las deudas que ciertos personajes habian contrafdo con el propósito de apoyar a la Hacienda Real; deudas entre las cuales se encontraban los «... cambis presos per los officials reals dels dotze milia ducats prestats [por la Diputación] per a la guerra contra los agermanats .... ${ }^{50}$. Otras, las 2.100 libras utilizadas en 1523 para saldar los débitos adquiridos por las finanzas regias con Gaspar Felipe Cruylles y Francesc de Artés con cargo al préstamo de 2.000 ducados concedido en octubre de 1522 s1.

Los oficiales de la Diputación, en efecto, abonaron las sumas indicadas en el párrafo anterior a terceras personas y no al virrey porque éste habfa recurrido al prestamismo privado; ofreciendo como garantía los empréstitos

\footnotetext{
4B Algunos de ellos, como Miquel Junyent o Baltasar de Cardona, son citados por Viciana; aunque desconocemos cuántos hombres se encuadraban en las unidades comandadas por dichos capitanes. Lo cual, por otra parte, tampoco es objetivo directo del presente trabajo (Cfr. VICIANA, Martín de, op. cit., IV, pág. 345).

49 Viclana, Martín de, op. cit., IV, pág. 344. Cit. supra, nota 33.

so Como luego se indicará, la participación de of iciales reales en ese endeudamiento mediante letras de cambio se limita a cobrar el importe de éstas de aquellos particulares a cargo de los cuales se giraban las letras (Cit. supra, CuADRo u. La cita está sacada de: A.R.V., Generalidad, Quem de deutes del General (1508-1526), reg. 4977, f. 21r. Cfr. supra, CuADro i).

sl Doc. cit. supra, CUADRo $\mathrm{ll}$.
}

Hispania, LV1/2, nüm. 193 (1996) 497-515 
otorgados por la Diputacion con el único objetivo de eludir las limitaciones cronologicas impuestas por los responsables de dicha institución.

Ya hemos indicado páginas atrás, por una parte, que los oficiales de la Diputación se habían reunido el 19 de enero de 1522 para aceptar como válidas las cantidades desembolsadas desde el verano anterior y para establecer en 12.000 ducados el tope máximo que se podría prestar a la Hacienda Real; tomando a cuenta de estos 12.000 ducados las anteriores cantidades: teniendo en cuenta - decían - el caudal gastado ya, el dinero líquido que restaba por entregar a los responsables de las finanzas regias supondría unos 3.000 ducados (3.150 libras), aproximadamente. No habíamos dicho todavia, sin embargo, que esos oficiales condicionaron la ejecución de este acuerdo a la aceptación por parte del virrey de unas condiciones determinadas: el reconocimiento, mediante documento público expedido por la Cancillería virreinal, del préstamo concedido; y la consignación del dinero prestado a lo que se recaudara por las multas y sanciones impuestas a los agermanados o, en su defecto, al servicio votado en las primeras Cortes que se celebraran ${ }^{52}$.

Es indudable que la dilación en el cumplimiento de estas condiciones por parte de Hurtado de Mendoza, relacionada con la desorganización burocrática del periodo, cauś cierto nerviosismo en los responsables de la Diputación ${ }^{53}$. Aunque, en el entretanto, el virrey consiguí que determinadas personas le anticiparan 3.000 ducados girando a Medina del Campo diversas letras de cambio; la devolución de los cuales, con sus correspondientes intereses, efectu6 la Diputación en octubre de $1522{ }^{54}$.

\section{CUADRO VI \\ INTERESES DE LAS IETRAS DE CAMBIO UTILIZADAS EN 1522 PAra SUBVENIR aL EuERCTTO REAL 55}

\begin{tabular}{|c|c|c|c|}
\hline Titular & Pagado al virrey & Papado por la Diputacion & Interes \\
\hline$\overline{\text { Varios }}{ }^{(2)}$ & $1.575 \mathrm{I}$. & $1.6531 .19 \mathrm{s.} 1 \mathrm{~d}$ & $\overline{5^{\prime} 01 \%}$ \\
\hline J. Beneyto & $525 !$ & $551 \mathrm{l} 4 \mathrm{~s} .11 \mathrm{~d}$. & $500 \%$ \\
\hline M. de la Torre & 5251. & $525 \mathrm{l}$ & - \\
\hline P. de P. Andreu & 5251. & 551 l. $15 \mathrm{~s}$. & $510 \%$ \\
\hline Total & $3.150 \mathrm{l}$. & $3.281 \mathrm{l} .19 \mathrm{~s}$ & $4^{\prime} 19 \%$ \\
\hline
\end{tabular}

(a) G. F. Cruylles (doncel), F. de Artés (doctor en ambos derechos) y A. Usodemar (mercader genovés).

52 A.R.V., Generalidad, Provisions, reg. 2972, ff 167r.-169v. y 322r.-325v,

53 En efecto, aunque el pertinente documento virreinal está fechado el 4 de abril del año 1522, los diputados no tuvieron constancia de su expedición hasta el 6 de octubre; que es cuando ordenaron la ejecución del acuerdo adoptado en enero: a comienzos de agosto todavía habian enviado una embajada solicitando al virrey su redacción (A.R.V., Generalidad, Procesos y papeles varios, reg. 2520 , ff. s./núm..; A.R.V., Generalidad, Provisions, reg. 2972, ff. 300v.-303v. y 321r.-321v;; IDEM, Generalidad, Albaranes, reg. 90, ff. 26r. y 30r. Cfr. supra, con las fechas especificadas en el CUADRo II).

54 Las fuentes dicen «... la fira de Medina de mag [mayo] primer vinent ....", que nosotros identificamos -a pesar de lo escrito sobre este tema por el prof. García Cárcel- con Medina del 
En el caso, además, de que la diferencia entre lo recibido por la Hacienda Real —capital prestado por los particulares-y lo pagado por la Diputación pueda ser considerado como el interés de las letras de cambio, podremos afirmar que éste se situó en el entorno del 5 por cien; las cifras presentadas en el CUADRO VI asi nos lo indican ${ }^{56}$.

Pero esta situación, por otra parte, se repitió cuando, en octubre de 1522, la Diputación aprobó la concesión de otro préstamo; pues Diego Hurtado de Mendoza volvio a encontrarse ante la misma tesitura a la que se había tenido que enfrentar en enero de ese mismo año: aceptar las condiciones que le imponían los diputados para recibir su importe ${ }^{57}$.

En esta ocasión, el virrey recurrió a Gaspar Felipe Cruylles y Francesc de Artés - concertando con éstos que le prestaran los 2.000 ducados a los que ascendía el empréstito- para adelantar el cobro de la suma concedida porque entre las cláusulas impuestas por los oficiales de la Diputación se encontraba una y según la cual el importe de dicho préstamo debía ser desembolsado en dos pagas: una primera, de 1.500 ducados, seis meses después de la expedición por parte de la Cancillerfa virreinal del texto en el que se reconocía la deuda; y otra segunda, de 500 ducados, a los tres meses de la anterior. Si esta periodización no fue observada es, sin duda, porque la Diputación cumplió con retraso sus obligaciones: acuciado el virrey por sus necesidades económicas, de cara a la rendición de Játiva y Alcira, el pertinente reconocimiento de la deuda con la Diputación fue expedido por el notario y

Campo; por celebrar ésta sus ferias en mayo y octubre (Doc. cit. supra, nota 42; y GARCiA CARCEL, Ricardo, Las Germanías de ...., 2." ed., pág. 146. Cfr., sin embargo, CARANDE, Ramón, Carlos V y sus banqueros, 3 vols., 4." ed., Barcelona 1990, I, págs. 331-333; y VAZqUEZ DE PRADA, Valentín, Historia Económica y Social de España (III): los siglos xVI y XVII, Madrid 1978, págs. 539 y 680 ).

Desde que $\mathrm{R}$. de Roover publicara su clásico sobre la letra de cambio, numerosos han sido los investigadores que han señalado la utilización de éstas para fines no exclusivamente comerciales. Cfr. DE ROOVER, Raymond, L'evolution de la lettre de change $\left(X N^{e}-x V m{ }^{e}\right.$ siècles), Paris 1953; LAPEYRE, Henry, Simón Ruiz et les «asientos» de Philippe II, París 1953; VAzQUEZ DE PRADA, Valentín, Lettres marchandes d'Anvers, 4 vols., Paris s. d., I, págs. 111-135; VILAR, Pierre, La Catalogne dans l'Espagne moderne. Recherches sur les fondements économiques des structures nationales, 3 vols., Paris 1962, I, págs. 563-565; HeERs, Jacques, Occidente durante los siglos XIV y XV. Aspectos económicos y sociales, 2." ed, Barcelona 1984, págs. 183-185; Pounds, N. J. G., op. cit., págs. 147, 470-473 y 481-487; o SPuFFORD, Peter, op. cit., págs. 328-332, 334, 340 y 505-508. Una reciente aproximación, desde la rica óptica valenciana, es Igual Lus, David, Valencia y Sevilla en el sistema económico genovés de finales del siglo $\mathrm{x} r$. València i la Mediterrània medieval: Revista d'Història Medieval, 2 (1992), págs. 79-116.

ss Fuentes: Elaboración propia a partir de los datos consignados en el CUADRo it y en A.R.V., Generalidad, Procesos y papeles varios, reg. 2520, ff. s./núm.

56 Debemos aclarar, sin embargo, al abordar este punto que ignoramos la causa por la cual al mercader Miquel de la Torre no se le abonaron intereses; cuando él participó, como los demás personajes citados en el CuAdro vi, en la operación crediticia efectuada con las letras de cambio.

57 A.R.V., Generalidad, Provisiones, reg. 2972, ff. 332r., 348v.-350r. y 475v. 477 r.

Hispania, LVL/2, núm. 193 (1996) 497-5i5 
escribano real Luis Domínguez el 6 de noviembre de 1522 s8; agobiada, sin embargo, por las dificultades financieras, nuestra institución tardó más de un año en efectuar la última devolución a los dos individuos que habían adelantado el dinero. Por eso, la cuantía de este empréstito (2.100 libras) figura en la contabilidad de la Diputación dentro del ejercicio contable de 1523; cuando la guerra ya habia terminado ${ }^{59}$.

\section{EPílogo}

Nuestros números, así pues, confirman lo que ya sabiamos desde que el prof. García Cárcel estudiara en su trabajo sobre las Germanías de Valencia el "dinero de la guerra": que la máxima concentración en los ingresos de las arcas reales se produjo en el periodo septiembre/noviembre de $1521 \mathrm{y}$, después, durante octubre y noviembre de $1522{ }^{60}$. Pero, después de analizar todas las objeciones descritas en los apartados anteriores ${ }^{61}$, todavía cabe preguntarse si estamos hoy por hoy en condiciones de precisar con la exactitud que desearíamos el dinero que realmente se gastó la Diputación del General valenciana para cooperar en el sostenimiento del ejército antiagermanado.

\section{CUADRO VII \\ Gastos totales de La DipUtación POR SU APORTación AL FINANCIAMIENTO DEL EIERCITO ANTIAGERMANADO ${ }^{62}$}

\begin{tabular}{lc} 
Año & \multicolumn{1}{c}{ Importe } \\
1521 & $8.7741 .17 \mathrm{~s} .8 \mathrm{~d}$. \\
1522 & $3.7011 .19 \mathrm{~s}$. \\
1523 & 2.1001. \\
TOTAL & $14.5761 .16 \mathrm{s.8 \textrm {d }}$. \\
DIFERENCIA con el límite & \\
de 14.700 libras & $-1231.3 \mathrm{s.} 4 \mathrm{~d}$.
\end{tabular}

Si nos dejarámos llevar exclusivamente por lo que dice la documentación generada por la Diputación -libros de actas, protocolos y contabilidad-, cuyas cifras hemos sintetizado en el CuADro vin, podríamos afirmar que la

58 A.R.V., Real Cancillería, Itinerum lugartenencia Mendoza y Cavanilles, reg. 414, ff 40r.-42r. Sobre la escribania y los escribanos reales al servicio del virrey y de la Real Audiencia valenciana, cfr. CANET APARISI, Teresa, La magistratura valenciana ...., págs. 103-125.

59 Doc. cit. supra, CuADro It.

60 Garcta CÁrCel, Ricardo, Las Germanias de ..., 2." ed., págs. 140 y 143. Cit. también en Pinilla Pérez de Tudela, Regina, Valencia y doña ...., pág. 57; y Pinilla Pérez de Tudela, Regina, El virreinato conjunto ...., pág. 225.

61 Vid. supra, «2. EL INICIO DE .....); y «3. LA APORTACí́n TOMA ....».

62 FUENTES: Doc. cit. supra, CuADRos I y il; así como notas 29 a 33. Elaboración propia. 
Diputación no alcanzó la meta de 14.700 libras que se había establecido: en este sentido, debemos indicar que los gastos especificados en esa documentación son los únicos plenamente constatados; a diferencia, como anteriormente se ha indicado, de otros que cita la tesorerfa general.

El intento, así pues, de responder más o menos taxativamente el interrogante planteado unas líneas más arriba puede ser un ejercicio intelectual altamente arriesgado: la desorganización y las difícultades administrativas de la Diputación durante este periodo no hace más fácil, precisamente, nuestra labor. Así, mientras no se encuentre una solución más precisa, tendremos que limitarnos a recordar que la Diputación presto dinero a la Hacienda Real desde el comienzo mismo de la contienda; pero, también, a remarcar cómo la dispersión de los datos -fruto de esos graves e importantes problemas institucionales- nos obliga a aceptar la «version oficial» de los hechos:

a) Que la Diputación concedió, durante las Germanías, dos préstamos "graciosos" (sin interés) ${ }^{63}$ y voluntarios ${ }^{64}$ a la Hacienda Real para subvenir los gastos del ejército reunido por el virrey Hurtado de Mendoza por un importe total de 14.700 libras; $y$

b) que la Diputación desembolsó íntegramente las 14.700 libras tantas veces citadas a lo largo de las páginas anteriores.

Esa fue la everdad" que presentaron los responsables de las finanzas regias durante los años de la contienda (en los balances confeccionados desde la tesorería general); esa fue la "verdad" que asumieron Diputación y administración real cuando negociaron, a lo largo del año 1527, la consignación y recaudación de las 14.700 libras con cargo a las composiciones impuestas a ciertas ciudades y villas reales ${ }^{65}$; y esa fue también la "verdad", finalmente,

63 Cfr., a título de ejemplos, A.R.V., Maestre Racional, Cuentas de las Germanias (1567), reg. 9880, f. lv; y A.R.V., Generalidad, Proyisions, reg. 2972, f. 167r,, en donde se califica a esos empréstitos de «... prestech graciós de la (...) Generalitat (...) a la Regia Cort ...».

64 El estudio de la «voluntariedad» o no de aportaciones financieras como las aquí estudiadas es, en nuestra opinión, un asunto extremadamente complicado por factores de muy diversa índole (como, por ejemplo, la activa participación del Maestre de la Orden de Montesa en su condición de oficial de la Diputación y de la organización financiera que se encargó de gestionar el dinero del ejército real) que dejamos para más adelante; reservándolo para trabajos de mayor envergadura que éste (Sobre este tema, sin embargo, puede consultarse por el momento GARCíA CARCEL, Ricardo, Las Germanías de ...., 2. ${ }^{2}$ ed., págs. 147-148; Gll Pujol, Xavier, «Centralismo e Localismo? Sobre as relaçoes Politicas e Culturais entre Capital e Territórios nas Monarquias Europeias dos Séculos XVI e XVII»: Penélope. Fazer e Desfazer a História 6 (1991), págs. 119-144; ELLlotT, John Huxtuble, Una aristocracia provincial: la clase dirigente catalana en los siglos XVI y XVIT. España y su mundo (1500-1700), págs. 99-121; Elliotr, John Huxtuble, A Europe of Composite Monarquies: Past and Present 137 (1992), págs. 48-71).

65 A.R.V., Real Cancillería, Curiae Valentiae, reg. 1315, ff. 15lv.-155r.; IDEM, Generalidad, Provisions, reg. 2976, ff. 19v.-20r., 22r.-23r., 24r. y 34v.-36r.; PINILLA PÉREZ DE TUDELA, Regina, El virreinato conjunto ...., I, págs. 170-175 y II, págs. 110-118. Los plazos de cobro negociados no llegaron a cumplirse por la convocatoria a Cortes antes de iniciarse el proceso de recaudación.

Hispania, LVI2, núm. 193 (1996) 497-515 
asumida cuando en las Cortes de 1528 se tomaron a cuenta de cierto servicio votado en ellas las 14.700 libras aque en lo temps de la revolució del present regne foren prestades a la regia cort" por la Diputación: esa revolución era la agermanada; y la formula adoptada, "cessio per via de restitució de las consignaciones acordadas el año anterior ${ }^{66}$.

Que esta «verdad coincida con la realidad es otra cosa; aunque los datos numéricos presentados, apenas diferentes de los que ya conocíamos, vean reducida su importancia dentro de nuestra investigación ante dos hechos que son, en última instancia, las caras de una misma moneda:

1) En primer lugar, la actuación de personajes como Bernat Despuig o Berenguer Ciurana, que mezclaron sus obligaciones en diferentes instituciones - la Diputación, en el caso de B. Despuig- con sus responsabilidades en la intendencia del ejército comandado por el virrey.

2) En segundo lugar, por otra parte, las graves repercursiones que tuvo para el funcionamiento de la Diputación la supuesta injerencia de los agermanados en su burocracia: la dicotomía entre un «aparato oficial» (el radicado en la ciudad de Valencia) controlado por los líderes de la revuelta y unos diputados actuando, de hecho, en el bando realista junto al virrey dejo en la Diputación - igual que en otras instituciones- unas huellas cuya señal iba a perdurar durante mucho tiempo.

Éstas dos -y la cronología de las pagos-- son, desde luego, las principales ensenanzas que podemos extraer de las páginas anteriores.

66 GaRCiA CARCEL, Ricardo, Cortes del reinado ...., págs. 10-11; A.R. V., Generalidad, Provisions, reg. 2977, ff. 66r.-69v.; IDEM, Generalidad, Clavería, reg. 792, passim; cfr. PINILLA PÉrEZ DE TUDELA, Regina, El virreinato conjunto ..... págs. 235-236, 305 y 319 . El acuerdo se ejecutó con cargo al ejercicio económico de 1529.

Hispania, LVV2, núm. 193 (1996) 497-515 